\title{
Central Giant Cell Granuloma of the Mandible: A Case Report
}

\author{
Babacar Tamba ${ }^{1,2, *}$, Mouhammad Kane ${ }^{1}$, Mamadou Diatta ${ }^{1}$, Bintou Catherine Gassama ${ }^{1}$, \\ Alpha Kounta ${ }^{1}$, Abdou Ba ${ }^{1}$, Ndeye Fatou Kebe', Soukeye Dia Tine ${ }^{1,2}$ \\ ${ }^{1}$ Department of Oral Surgery, Odontology and Stomatology Institute, Cheikh Anta Diop University, Dakar, Senegal \\ ${ }^{2}$ General Hospital Idrissa Pouye, Dakar, Senegal
}

\section{Email address:}

babacartamba@yahoo.fr (B. Tamba), kanemouhammad@yahoo.fr (M. Kane), diattamap@gmail.com (M. Diatta), cathygueye2000@yahoo.fr (B. C. Gassama), dentalpha@yahoo.com (A. Kounta), abdouba301@ hotmail.com (A. Ba), nfkd12@yahoo.fr (N. F. Kébé), soukeye.diatine@gmail.com (S. D. Tine)

*Corresponding author

\section{To cite this article:}

Babacar Tamba, Mouhammad Kane, Mamadou Diatta, Bintou Catherine Gassama, Alpha Kounta, Abdou Ba, Ndeye Fatou Kebe, Soukeye Dia Tine. Central Giant Cell Granuloma of the Mandible: A Case Report. International Journal of Clinical Oral and Maxillofacial Surgery. Vol. 6, No. 2, 2020, pp. 40-43. doi: 10.11648/j.ijcoms.20200602.14

Received: July 7, 2020; Accepted: August 3, 2020; Published: August 13, 2020

\begin{abstract}
The central giant cell granuloma (CGCG) of the jaws is a rare benign tumour of the mandible (lower jaw) and the maxilla (upper jaw) characterized by destruction of the bone, loss of symmetry of the face and displacement of teeth and tooth germs, especially in younger patients. It is asymptomatic and present with slow growth often accompanied by dental mobility. The removal of this tumour is mutilating and is followed prosthetic rehabilitation. The aim of this study was to report a case of central giant cell granuloma localizated to the symphyseal region in a young patient. The case reported is that of a 14-year-old girl who received a consultation for a tumor in the symphysical region causing an aesthetic impact. The tumor was firm, painless and had been developing for about a year. The cortical were broken in places, in transverse, sagittal and coronal sections. The treatment consisted of her excision under general anesthesia causing a significant loss of substance. The tumor mass, very hemorrhagic, was extended to the buccal floor. At the end of the intervention, a significant loss of substance was observed. Two months later, a partial adjunct prosthesis was performed. The anatomo-pathological examination showed of several multinucleated giant cells, a few histiocytes, lymphocytes and fibroblasts. The removal of this aggressive tumour remains mutilating, with significant psychological repercussions. More recently, antiangiogenic therapy with interferon alpha has been successfully applied.
\end{abstract}

Keywords: Central Giant Cell Granuloma, Mandible, Removal

\section{Introduction}

In 1953, Jaffe described this lesion as a «giant-cell reparative granuloma». The term «reparative» has been abandoned since due to the differentiation of central giant cell lesions between aggressive and non-aggressive lesions [1].

The central giant cell granuloma (CGCG) is an infrequent, osteolytic and aggressive benign jaw tumor [1]. It is often asymptomatic and present with slow growth often accompanied by dental mobility [2]. According to Chrcanovic, the lesion was more prevalent in women than in men. The mean age of the patients was $25.8 \pm 15.3$ years. The highest prevalence in the second and then third decade of life [3]. Its etiology remains unknown. There are two types of clinical progression: nonaggressive and aggressive. The aggressive forms are found mainly in younger patients. Some factors such as local trauma, inflammation, intraosseous hemorrhage, and genetic anomalies may be involved. However, the diagnosis can be made only by histological examination. The removal of this tumour is mutilating with significant aesthetic and psychological repercussions. Pharmacologic agents have been used as alternatives to surgical management [3]. The authors report a case of a central giant cell granuloma developed in the symphysical and alveolar regions. The treatment consisted of the removal 
of the tumour under general anaesthesia.

\section{Case Report}

A 14-year-old girl was seen for a tumor in the symphysis area that caused aesthetic damage and had been evolving for about a year. Exobuccal profile examination showed a lower lip eversion with an erased lip and chin groove (figure 1). On endobuccal examination, there was an outgrowth of the tumor towards the lower lip and a filling of the buccal floor. The mucous membrane was healthy. The tumor was firm, painless with the incisor block moved and the 41 absent (figure 1).

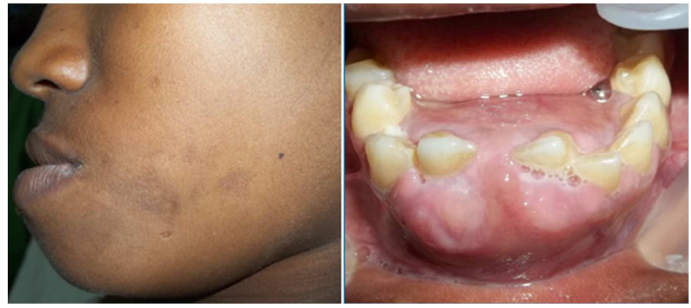

Figure 1. Preoperative view.

(left). Lower lip eversion erasing the lip chin groove, (right) Floor filling and dental movements.

The CT scan showed oval, hypodense, voluminous and blowing formation with thin bone walls. It measured about $50 \times 38 \times 32 \mathrm{~mm}$. The cortical were broken in places, in transverse, sagittal and coronal sections (figure 2).
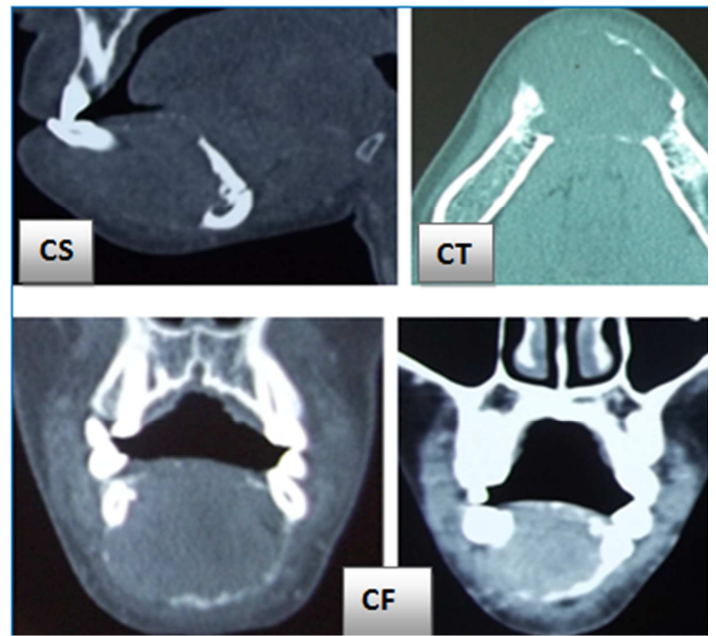

CS: sagittal section, CT: cross section, CF: frontal section.

Figure 2. Voluminous radioclear image blowing cortical arteries with significant ruptures in places.

Clinical and paraclinical signs were in favour of a benign osteolytic tumor. The treatment consisted of the removal of the tumour under general anaesthesia. After extraction of the incisor block, two incisions were made at the vestibular and lingual sulcular level from the 44 to the 34 . A detachment combined with dissection allowed the mucosa to be released from the tumor mass. The removal of this mass, which is very adherent to the bone, was carried out with a gouge forceps. The tumor mass, very hemorrhagic, was extended to the buccal floor. At the end of the intervention, a significant loss of substance was observed (figure 3 ). The operating part consisted of 5 irregular tissue fragments and 5 teeth, the incisivo-canine block (figure 3).

The lower lip was without dentoalveolar support and healing was complete fifteen days later (figure 4).

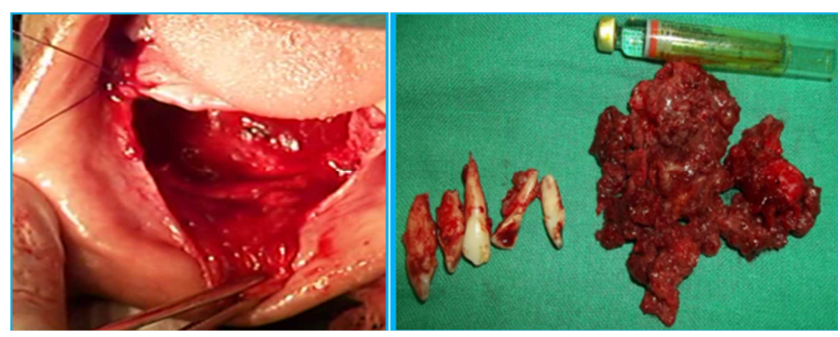

Figure 3. Peroperative view.

(left) Significant loss of substance after excision: (rigt) The operating part consisted of 5 tissue fragments and teeth.

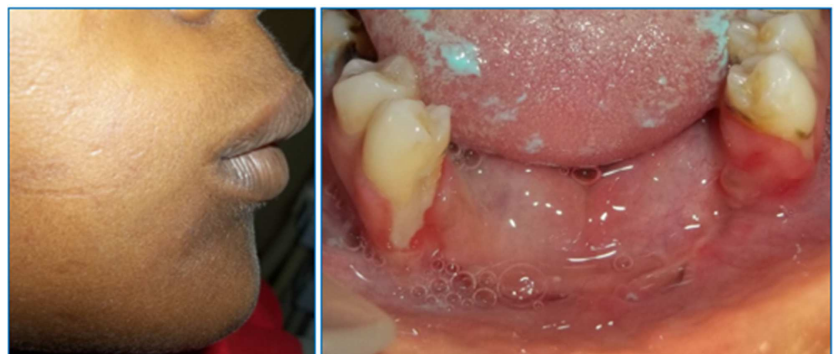

Figure 4. Exobuccal and: endobuccal controls, 15 days later.

The anatomo-pathological examination was in favor of the central granuloma giant cells. It was a connective tumor consisting of several multinucleated giant cells, a few histiocytes, lymphocytes and fibroblasts. It is associated with congestive vascular cavities and bone spans (figure 5). Two months later, a partial adjunct prosthesis was performed (figure 6). The patient followed up 3 months after the surgery. There was no residual symptomatology.

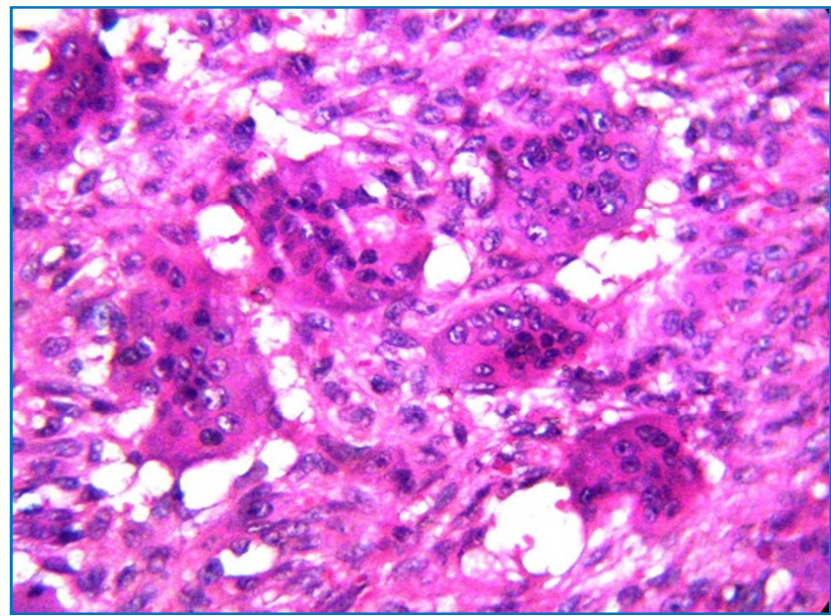

Figure 5. Multinucleated giant cells with vascular cavities. 


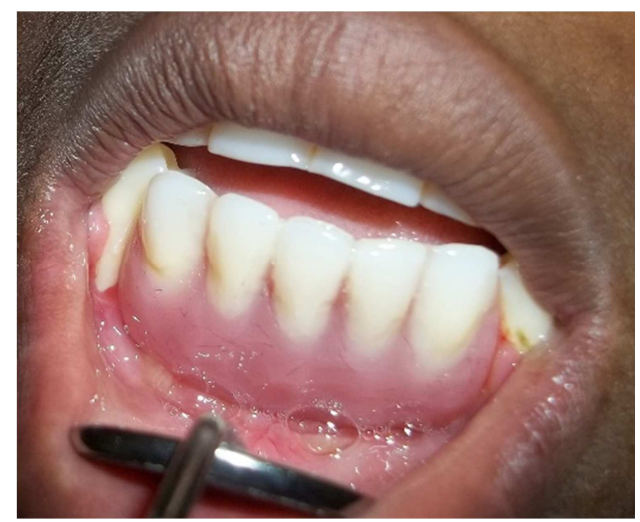

Figure 6. Prosthetic rehabilitation.

\section{Discussion}

The central giant cell lesion of the jaw is a rare benign tumour with an unknown aetiology accounting for up to $7 \%$ of tumours in the mandible and the maxilla [1]. CGCG is a benign osteolytic tumor discovered most often before the age of 30 due to its asymptomatic nature. Females are predominantly affected in $2 / 3$ of cases before age 20 years [4]. CGCG is most often found in the mandible and in young women [4]. The particularity of this lesion lies in the difficulty of its clinical and radiographic diagnosis. The deformation of the jaws as well as the dental movements and mobilities it causes most often lead to consultation. The lesions had a mean size of $3.9 \pm 2.1 \mathrm{~cm}$ [3]. Non-aggressive lesions do not perforate the cortical bone, and the recurrence rate is low. Aggressive types of tumours are usually expansive and rapidly grow, causing pain, bleeding, and displaced and loose teeth. [5]. The delay to consult can be up to 8 years according to Abdelqader [6]. Computed tomography (CT) plays an important role in determining the size and extent of the lesion and the presence of cortical expansion and bony destruction. The CT often shows a hypodense unilocular or multilocular lesion associated with root resorptions. Cortical ruptures are present [5]. CGCL are expansile, radiolucent and often multiloculated lesions, rarely mixed with opacities, with scalloped and mostly well-defined but non-corticated borders. With increasing size, multilocularity is more often noticed. Disappearance of the lamina dura, root resorption or, more often, tooth displacement are additional findings. Intralesional wavy bony septa are characteristic [1]. The beam cone also gives precise information on the limits of the lesion as well as on anatomical obstacles such as the chin foramen and the mandibular canal $[6,7]$.

The differential diagnosis is made with other giant cell tumors. Three entities can be found: the brown tumor of hyperparathyroidism (extensive, finely compartmentalized defects), the aneurysmal cyst (intraosseous hematoma) and cherubism or familial multilocular cystic disease of the maxilla $[1,7]$. The peripheral giant cell granuloma is thought to arise from the periosteum or the periodontal ligament after local irritation or chronic trauma. These lesions have been described as reddish or purple with a smooth surface and a consistency that varies from soft to firm [7].

The removal of this tumour is mutilating with significant aesthetic and psychological repercussions, hence the need for prosthetic rehabilitation [8]. Teeth that are displaced and/or mobile in relation to this tumour are extracted due to the underlying bone scarcity [9]. The surgical specimen is reddish-brown in color, sometimes partially necrotic. Although themost common therapy is surgical curettage, the high recurrence rate, especially in aggressive lesions, has raised concern and led to a search for other treatment options [8].

Intra-tumor administration of corticosteroids has shown favourable results with Interferon $\alpha$, administered as monotherapy in aggressive CGCG treatment, also appears to be able to stop the growth of lesions, sometimes reducing their size.

Interferon alpha is known for its inhibition of the angiogenesis in the tumours and its application has recently been instituted in these types of lesions. Interferon alpha administration in the treatment of aggressive CGCG seems capable of interrupting the growth of the lesions, even reducing the size. However, an associated surgery is often needed to eliminate the lesion. [10, 11, 12]. Although the calcitonin's mechanism of action remains unclear, it is suggested that it has a direct inhibitory effect of the osseous reabsorption through the osteoclasts, increasing the absorption of calcium of the bones and favouring the osseous cicatrisation [13].

It is often necessary to add a surgical procedure to eliminate the lesion a cytokine called RANKL, strongly involved in the activity of osteoclasts, of which giant cells are part, has been discovered in CGCG [13]. The recurrence rate after excision represents about $50 \%$ with a risk of malignant transformation into sarcoma between 10 and $12 \%$ [14].

Histopathologically, it has a proliferation of multinucleated giant cells within a connective tissue formed of ovoid or tapered mesenchymal cells. $[15,16]$.

The lesion consists of spindle-shaped fibroblastic or myofibroblastic cells, loosely arranged in a fibrous, sometimes fibromyxoid, vascularized tissue with haemorrhagic areas, haemosiderin deposits, macrophages, lymphocytes, granulocytes and, rarely, plasma cells. Especially in the haemorrhagic areas, evenly dispersed or small clusters of osteoclast-like giant cells are found. In addition, traversing collagen bundles are present, often accompanied by metaplastic bone formation, giving the lesion a somewhat lobular appearance. Mitoses are frequently found [16].

Higher overall expression of VEGF in CGCG might lead to increased vascularity as well as more destructive nature. VEGF is involved in tumor growth via the mechanism of neoangiogenesis to meet the oxygen and nutrient requirement of tumor cells and is involved in pathogenesis [17].

The CGCL is a localized benign but sometimes aggressive osteolytic proliferation consisting of fibrous tissue with haemorrhage and haemosiderin deposits, presence of 
osteoclast-like giant cells and reactive bone formation [1].

The CGCG is a very mutilating benign tumor whose removal has aesthetic and functional repercussions that can go as far as the interruption of mandibular continuity. 3D imaging, such as the scanner or the beam cone, allows for better planning of the surgical procedure and the prosthetic project [8]. The recurrence rate of CGCG ranges from 10 to $15 \%$. Aggressive lesions (22.8\%) recurred after surgical treatment, compared to non-aggressive lesions (7.8\%) [3]. The following factors showed a statistically significant increase in the recurrence rate: curettage, enucleation or marginal resection in relation to segmental resection, aggressive lesions, cortical bone perforation, and tooth root resorption [3].

\section{Conclusion}

The management of CGCG can include conventional surgery with or without medical adjunctive treatment or resection in-bloc for the aggressive variant. Histological findings are not predictive of biological behaviour. The treatment of CGCL is careful enucleation. In case of recurrences, more extensive surgery should be considered. Administration of calcitonin or glucocorticoids (intralesional) has proven effective in some cases. More recently, antiangiogenic therapy with interferon alpha has been successfully applied.

\section{References}

[1] Barnes L. WHO Odontogenic Tumours. IARC Press; 2005, 285-330.

[2] Chuong R, Kaban LB, Kozakewich H, Perez-Atayde A. Central giant cell lesions of the jaws: a clinicopathologic study. J Oral Maxillofac Surg 1986; 44: 708-713.

[3] Chrcanovic BR, Gomes CC, Gomez RS. Central giant cell lesion of the jaws: an updated analysis of 2270 cases reported in the literature. J Oral Pathol Med 2018; 47: 731-739.

[4] Whitaker SB, Waldron CA. Central giant cell lesions of the jaws. A clinical, radiologic, and histopathologic study. Oral Surg Oral Med Oral Pathol 1993; 75: 199-208.

[5] Stavropoulos F, Katz J. Central giant cell granulomas: a systematic review of the radiographic characteristics with the addition of 20 new cases. Dentomaxillofac Radiol. 2003; 31: 213-217.
[6] Abdelqader S, Roche N, Manfredi L, Papon JF, Maman L, Ferré F. Up-to date review and case report giant-cell granuloma: 2 cases reports. J Oral Med Oral Surg 2018; 24: 182-186.

[7] Bonolis A, Euvrard E, Meyer C, Louvrier A. Central giant-cell granuloma located in the mandibular symphyseal region of a child. J Oral Med Oral Surg 2018; 24: 53-56.

[8] Ahossi V, Vincent S, Duvillard C, Larras P, Petrella T, Perrin D. Giant cell reparative granuloma of the maxilla: a case report. Rev Odontostomatol 2010; 39: 135-144.

[9] Pham Dang N, Longeac M, Picard M, Devoize L, Barthélémy I. Central giant cell granuloma in children: presentation of different therapeutic options. Rev Stomatol Chir Maxillofac Chir Orale 2016; 117: 142-146.

[10] Abdo EN, Alves LC, Rodrigues AS, Mesquita RA, Gomes RS. Treatment of a central giant cell granuloma with intralesional corticosteroids. Brit J Oral Maxilfac Surg 2005; 43: 74-76.

[11] Kurtz M, Mesa M, Alberto P. Treatment of central giant cell lesion of the mandible with intralesional glucocorticosteroids. Oral Surg Oral Med Oral Path Oral Rad Endo 2001; 91: 636637.

[12] Saim Y, Mutan HA. Management of central giant cell granuloma of mandible using intralesional corticosteroids: case report and review of literature. J Oral Maxillofac Surg 2013; 71: 721-722.

[13] De Lange J, van den Akker HP, Engelshove HA, van den Berg $\mathrm{H}$, Klip H. Calcitonin therapy in central giant cell granuloma of the jaw: a randomized double-blind placebo-controlled study. Int J Oral Maxillofac Surg 2006; 35: 791-795.

[14] Barthélémy I, Mondié JM. Giant cell tumors and pseudogiant cell tumors of the jaws. Rev Stomatol Chir Maxillofac 2009; 110: 209-213.

[15] Suárez-Roa MDL, Reveiz L, Ruíz-Godoy RLM, AsbunBojalil J, Meneses-García A. Interventions for central giant cell granuloma (CGCG) of the jaws. The Cochrane Library 2009, Issue 4, 16p.

[16] Kudva A, Cariappa KM, Dhara V, Solomon M. Central giant cell granuloma: An uncommon presentation. Oral and Maxillofacial Surgery Cases 4, 2018; 135-140.

[17] Saghravaniana N, Mohtashama N, Vahedib M, Ghazia N, Aghaee MA. Immunohistochemical evaluation of VEGF and tryptase forangiogenesis and mast cell counting in giant cell granulomasof the jaws. J Oral and Maxillofac Surg Med and Pathol 2018; 30 (4): 365-370. 